\title{
Association of Plasminogen Activator Inhibitor-1 and Cardiovascular Events Development in Patients with Prediabetes
}

\author{
YelenaLaryushina ${ }^{1}$ D, ViktoriyaParakhina ${ }^{1 *}$ (D) LyudmilaTurgunova $^{1}$ (D), DinaraSheryazdanova ${ }^{1}$ (D), RaushanDosmagambetova ${ }^{1}$ (D) \\ Anar Turmukhambetova ${ }^{2}$ (D) Olga Ponamareva $^{3} \mathbb{D}$, Maria Orbetzova ${ }^{4}$ (D) \\ ${ }^{1}$ Department of Internal Medicine, Karaganda Medical University, Karaganda, Kazakhstan; ${ }^{2}$ Department of Strategic \\ Development and Science, Karaganda Medical University, Karaganda, Kazakhstan; ${ }^{3}$ Department of Biochemistry, Karaganda \\ Medical University, Karaganda, Kazakhstan; ${ }^{4}$ Department of Endocrinology, Medical University of Plovdiv, Plovdiv, Bulgaria
}

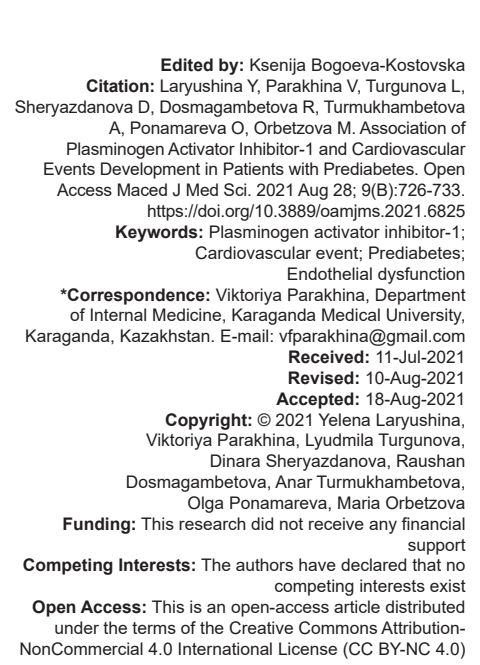

\section{Abstract}

BACKGROUND: Plasminogen activator inhibitor-1 (PAI-1) is a marker of endothelial dysfunction (ED) and a predictor of both the development of type 2 diabetes mellitus, and a cardiovascular event (CVE). Its role in the CVE development was sufficiently studied in patients without carbohydrate metabolism disorders, and understudied in patients with prediabetes.

AIM: The research interest is the study of PAI-1 in patients with prediabetes and its effect on the CVE development.

MATERIALS AND METHODS: The case-control study of 168 patients aged from 18 to 65 was carried out among the local population from January to December 2019. After clinical examination, patients were divided into three groups: Group $1(n=55)$ - patients with prediabetes and with CVE; and Group $2(n=93)$ - patients with prediabetes and without CVE; the control group $n=20$.

RESULTS: Differences in PAl-1 level were found in groups $1(\mathrm{Me}=30718.6 \mathrm{pg} / \mathrm{ml})$ and $2(\mathrm{Me}=24692.0 \mathrm{pg} / \mathrm{ml}$ $p \leq 0.001)$, even greater differences were found in both groups compared to the control one $(p \leq 0.001)$. The correlation analysis has found in both group influences such IR indicators as fasting glucose, IR-HOMA index glucagon, and C-peptide to elevation of PAI-1. These findings indicate that with an elevation of the PAI-1 level, the concentration of fasting glucose, glucagon, C-peptide, and scores of IR-HOMA index increase in both groups. The Binary regression analysis has demonstrated that an elevation of the PAl-1 biomarker increases the likelihood of CVE by 3.3 fold in patients with prediabetes $(p \leq 0.01)$. In addition to, a model has been derived for assessing the risk of CVEs in patients with prediabetes.

CONCLUSIONS: Elevation of PAI-1 concentration is associated with insulin resistance which leads to ED, and further development risk of CVE in patients with prediabetes.

\section{Introduction}

At present, cardiovascular diseases (CVD) keep the lead around the world with the ever growing rates and are the main cause of death from non-communicable diseases. Myocardial infarctions and strokes are likely to be attributable to the causes of death. According to the WHO [1], 17.9 million people died from CVD in 2016, accounting for $31 \%$ of all deaths worldwide. In Kazakhstan, this figure was $25.9 \%$ [2]. The risk factors, such as type 2 diabetes mellitus (T2DM), hyperlipidemia, and hypertension are the determinants for high cardiovascular risk (CVR). Behavioral risk factors, including obesity, smoking, unhealthy diet, low physical activity, and alcohol consumption also contribute to the CVD development.

T2DM is the most common disease characterized by a carbohydrate metabolism disorders, and the development of macrovascular complications [3]. The fundamental, prospective 20-year Framingham heart study shows the importance of the association between diabetes and CVD. [4].

There are only a few studies devoted to the cardiovascular event (CVE) risk in prediabetic patients. Thus, a study by Selvin et al. [5] has found that increased glycated hemoglobin is associated with the development of both diabetes, and CVE. The glycated hemoglobin level of over $6 \%$ was considered a risk of diabetes, and a high risk of CVE.

The issue of endothelial dysfunction (ED) in T2DM has been studied in numerous studies. Complex intersections of the metabolic pathways of insulin resistance (IR) and ED simultaneously affect the atherosclerosis, with no possibility to say exactly which of these processes increasingly damages a vessel wall. At the same time, hyperglycemia in DM induces the ED through oxidative stress, and also contributes to the accelerated atherosclerosis [6]. And thus, the ED and vascular disorders result in macroangiopathy and CVE in T2DM patients. 
There are several studies on the presence of ED in prediabetic patients. There are studies on the evaluation of ED in patients with metabolic syndrome, obesity [7] or with normoglycemia and the presence of IR [8]. In all these cases, IR played a crucial role in the ED development. Thus, ED is associated with IR and is one of the main mechanisms for the CVE development in patients with both prediabetes and T2DM [8], [9], [10] .

Plasminogen activator inhibitor-1 (PAI-1) biomarker is a vessel factor [11], a fast-acting inhibitor of fibrinolysis, considered as one of the risk factors triggering atherosclerosis [12] resulting in the risk of CHD development.

At the same time, the PAl-1 biomarker is considered as a predictor of T2DM. A prospective study titled The IR Atherosclerosis Study by Festa et al. [13], [14] found that the PAl-1 biomarker predicted the development of T2DM regardless of IR and other known risk factors (Body mass index [BMI], waist circumference [WC], gender, age, and smoking). T2DM developed in $140(16.6 \%)$ out of 843 patients after a 5 -year follow-up period.

However, there is still no evidence that the concentration of PAl-1 increases in vessel walls in T2DM patients before the development of atheromatous plaques.

The scientific novelty of this study is in the evaluation of the PAI-1 biomarker in prediabetic patients, the influence of the studied biomarker on the risk of CVE.

The interest of the study is also the level of this marker in patients with prediabetes and without CVE, at the risk stage. Clarification of the PAI-1role in the development of ED will expand the possibilities of early therapeutic effects on IR, which will reduce mortality from CVE in prediabetic patients.

\section{Aims}

The aim of the study was to study the effect of the PAI-1 biomarker on the CVE risk in patients with prediabetes.

\section{Materials and Methods}

\section{Patients}

The unmatched case-control study of 168 patients aged $18-65$ was carried out among the local population from January to December 2019. The first group consisted of patients with prediabetes who were admitted to the local regional cardiac surgery hospital due to acute coronary syndrome in the first $24 \mathrm{~h}$ after the onset of the first symptoms of a CVE. The second group consisted of patients with prediabetes without CVE with a medical history of newly diagnosed prediabetes according to screening data, who were randomly selected from various outpatient clinics of the city.

Patients with a documented diagnosis of acute myocardial infarction were included in the group with the presence of non-fatal CVE, based on the presence of ischemic symptoms, detection of an increase and/or regular dynamics of a decrease in cardio specific enzymes, coronary angiography data (presence of intracoronary thrombosis) in combination with pathological altered electrocardiogram (ECG) (diagnostically significant ST-segment elevation or newly registered left bundle branch block; pathological $Q$ wave on ECG).

Prediabetes was established according to the American Diabetes Association criteria [15]: - Glycated hemoglobin ( $\mathrm{HbA} 1 \mathrm{c})$ level $(\%)$ from $5.7 \%$ to $6.4 \%$ - and/ or fasting hyperglycemia from 5.6 to $6.9 \mathrm{mmol} / \mathrm{L}$ - and/ or impaired carbohydrate tolerance (impaired glucose tolerance) - after $2 \mathrm{~h}$ of oral glucose tolerance test (OGTT) after giving $75 \mathrm{~g}$ glucose - glycemia from 7.8 to $11.1 \mathrm{mmol} / \mathrm{l}$. Determination of prediabetes using glycated hemoglobin reflected the violation of carbohydrate metabolism over the past 2 months, which was important for its determination in patients with CVE, to exclude stress hyperglycemia in patients with CVE.

Thus, three groups were formed: Group 1(n = 55) - patients with prediabetes and the presence of CVE, Group $2(n=93)$ - patients with prediabetes and without CVE. The last group was a control group consisted of 20 respondents, aged 18-30, without any concomitant diseases.

The inclusion criteria were: Men and women aged 18-65 years who gave informed consent to participate in the clinical trial.

\section{Exclusion criteria were}

Patients with previously diagnosed T2DM or newly diagnosed diabetes using an OGTT, or patients with plasma glucose levels of $11.1 \mathrm{mmol} / \mathrm{L}$ or higher (200 mg/dL);

Patients with chronic kidney disease and renal dysfunction based on a glomerular filtration rate (chronic kidney disease-epidemiology collaboration) $\leq 90 \mathrm{~mL} / \mathrm{min} / 1.73 \mathrm{~m}^{2}$;

Pregnant women, people with severe mental and oncological diseases.

Research included questionnaires, anthropometry (measurement of height, weight, WC, and calculation of $\mathrm{BMI}$ ), measurement of blood pressure (BP), and determination of biochemical parameters: The level of $\mathrm{HbA} 1 \mathrm{c}, \%$, C-peptide, insulin, glucagon, fasting capillary blood glucose, fasting lipid profile blood test (total cholesterol, LDL, HDL, triglycerides), PAI-1 
biomarker, and IR index (IR)- HOMA was calculated. Research included questions of socio-demographic characteristics, heredity, history of chronic noninfectious diseases, taking antihypertensive drugs, and antiplatelet agents (anticoagulants).

Blood pressure (BP) was measured in accordance with the WHO guidelines using a mechanical tonometer (Microlife BP AG1-10) on both arms with a preliminary rest period of at least $10 \mathrm{~min}$ [16]. The smallest of three consecutive measurements was taken for calculations.

Height and weight were measured using a digital weighted stadiometer (TBEC RS-232). BMI was calculated using the formula: Body weight divided by the square of height in meters $\left(\mathrm{kg} / \mathrm{m}^{2}\right)$. (WC, $\left.\mathrm{cm}\right)$ was measured using an inelastic measuring tape at the midpoint between the lower edge of the last palpable rib and the top of the iliac crest. BMI was graded according to "Centers for Disease Control and Prevention": From 25.0 to $30.0 \mathrm{~kg} / \mathrm{m}^{2}$ as overweight, more than $30.0 \mathrm{~kg} / \mathrm{m}^{2}$ as various degrees of obesity. Abdominal obesity was considered if WC was over $94 \mathrm{~cm}$ in males, and over $88 \mathrm{~cm}$ in females. consent.

Before the study, all patients filled informed

\section{Sample size}

Sample size was calculated using the Kelsey method, EPI info software for unmatched case-control studies. The two-sided confidence level was 95\%, the statistical power was $80 \%$, and the ratio of unexposed cases to exposed cases was two. According to the literature review, we took data about prevalence patients with T2DM and CVE. Thus, the percentage of outcomes, in this case the prevalence of MACE cases (fatal myocardial infarction, stroke, patients after revascularization including coronary artery bypass grafting, and percutaneous coronary intervention) in patients with T2DM, was determined from previous studies. Thus, after calculation the minimum number of respondents with a CVE and prediabetes was 46 people (case), patients with prediabetes and without CVE (control) - 92 people.

\section{Ethical approval}

Research Protocol No. 309 has been approved on September 19, 2017, by the Local Ethical Committee, in accordance with the ethical principles of scientific research provided by the World Medical Association in the Declaration of Helsinki.

\section{Measurement of biochemical parameters}

The plasma with ethylenediaminetetraacetic acid was conserved in vials by aliquots and quickly frozen. The samples were stored at $-70^{\circ} \mathrm{C}$ for no more than 3 months. Determination of fasting lipid profile blood test (total cholesterol LDL, HDL, and triglycerides) was done from blood plasma by the method of selective precipitation with phosphotungstate and magnesium.

$\mathrm{HbA1c}$ was determined from capillary whole blood by reflectometry using the Nyco-Card test system.

Determination of insulin, glucagon, C-peptide was carried out by multiplex immunological analysis using XMap technology on Bioplex 3D.

\section{Measurement of PAl-1}

The method of magnetic bead-based multiplex immunoassay using XMap technology was used for PAI-1. The standard Milliplex map Human CVD Magnetic Bead Panel 1 (Millipore) kit was used to determine concentration of listed metabolites in accordance with "Override protocol" instruction of manufacturer. The study protocol included incubation of unknown, standard, and control samples with magnetic beads loaded with primary antibodies, revelation using detecting antibodies and Streptavidin Phycoerythrin Conjugated. Final step of the protocol was fluorescence registration using Bioplex 3D equipment (Luminex software). The coefficient of variation was $<20 \%$ for all detected analytes with minimum detectable concentration of PAl-1- $3489.3 \mathrm{pg} / \mathrm{ml}$.

\section{Calculation of IR-HOMA index}

IR-HOMA index was calculated using the formula (fasting insulin $(\mu \mathrm{U} / \mathrm{l}) \mathrm{x}$ fasting glucose $(\mathrm{mmol} / \mathrm{l}) / 22.5)$, values greater than 2.7 were considered as the IR.

\section{Statistical analysis}

The data previously were tested for normality of distribution by Kolmogorov-Smirnov, the distribution was not normal.

The differences between groups (Groups 1 and 2) were assessed by the nonparametric Mann-Whitney $U$ test, the differences between all three groups were assessed by the Kruskal-Wallis test. Assessment of the relationship of PAI-1 biomarker with indicators of IR, lipid profile, IR-HOMA index was carried out using Spearman's correlation coefficient.

Associations of PAl-1 with a CVE were calculated using a binary logistic regression model, and the data were log-transformed before calculating the model (dependent variable was presence or absence CVE in patients with prediabetes). Adjustment was done for gender, age and presence of hypertension. Linear regression was used to study the factors affecting the increase of PAI-1 biomarker (dependent variable level 
of PAI-1). Statistical analysis was performed using IBM SPSS Statistics, 22.0. The results were considered statistically significant at $p \leq 0.05$.

\section{Results}

The following differences were found in groups during studying the characteristics of the patients (Table 1).

\section{Table 1: Characteristics of patients}

\begin{tabular}{llll}
\hline Variables & Group 1 - CVE $(+)$ & Group 2 - CVE $(-)$ & p-level \\
\hline $\mathrm{n}$ & 55 & 93 & \\
Gender, $\mathrm{m}(\%) / \mathrm{f}(\%)$ & $35(63.6) / 20(36.3)$ & $26(34.6) / 49(65.3)$ & 0.02 \\
Age, (years) & $55.5(45.2 ; 60.2)^{*}$ & $53.0(42.5 ; 60.0)$ & 0.06 \\
$\mathrm{BMI},\left(\mathrm{kg} / \mathrm{m}^{2}\right)$ & $28.7(23.44 ; 33.7)$ & $28.7(26.1 ; 34.1)$ & 0.07 \\
Waist circumference, (cM) & $96.0(84.0 ; 113.5)$ & $97.0(86.5 ; 103.0)$ & 0.08 \\
Systolic BP, mm of mercury & $130.0(110.0 ; 132.5)$ & $130.0(110.0 ; 140.0)$ & 0.07 \\
Diastolic BP, mm of mercury & $80.0(70.0 ; 90.0)$ & $80.0(78.0 ; 90.0)$ & 0.06 \\
Hypertension, $\mathrm{n}(\%)$ & $37(67.2)$ & $58(77.3)$ & $\leq 0.001$ \\
Current smoker, $\mathrm{n}(\%)$ & $25(45)$ & $15(20)$ & 0.02 \\
Current treatment, $\mathrm{n}(\%)$ & & & \\
$\quad$ Calcium channel blocker & $1(1.8)$ & $1(1.3)$ & 0.09 \\
$\quad$ Beta blocker & $1(1.8)$ & $7(9.3)$ & 0.05 \\
$\quad$ ACE inhibitor & $12(21.8)$ & $20(26.6)$ & 0.05 \\
$\quad$ Thiazide diuretics & $3(5.4)$ & $8(10.6)$ & 0.08 \\
$\quad$ Aspirin & $17(30.9)$ & $31(41.3)$ & 0.05 \\
\hline CVE: Cardiovascular event, BP: Blood pressure, BMI: Body mass index. *Data presented as Me (Q25; \\
Q75); (\%). & & &
\end{tabular}

Male patients in Group 1 prevailed in 63.6\% of cases, while in Group 2, female patients prevailed in $65.3 \%$ of cases.

The median age of patients was practically the same in both groups and amounted to 55.5 years in Group 1, and 53.0 years in Group 2, respectively. There were no differences in the groups during studying BMI and WC. However, in both groups, BMI and WC were higher than normal, and reflected the presence of abdominal obesity (WC) and overweight (BMI) in patients of both groups.

The anamnesis study established a statistically significant ( $p \leq 0.001$ ) prevalence of arterial hypertension $(\mathrm{AH})$ in Group 2 patients, which occurred in $77.3 \%$ of cases. However, the level of systolic and diastolic blood pressure in both groups did not differ significantly and was within the range of high normal blood pressure. Analysis of antihypertensive therapy revealed in both groups more frequent use of ACE inhibitor drugs, compared with beta-blockers, thiazide diuretics, and calcium channel blockers. Antiplatelet therapy was used more frequent in Group 2 - in 41.3\% $(p=0.05)$ patients.

Analysis of behavioral factors revealed the prevalence of active smoking in Group 1, where 45\% $(p=0.02)$ of patients indicated the presence of a bad habit - smoking.

The following differences were revealed during studying biochemical parameters (Table 2).

IR indicators such as insulin, C-peptide, IR-HOMA index statistically significantly prevailed in group 1 in patients with prediabetes and CVE ( $p \leq 0.001)$.
Hence, in Group 1 in patients with prediabetes and the presence of CVE, the median insulin value was Me $29.26 \mathrm{mU} / \mathrm{L}$ (Q25; Q75 -23.56; 35.78), which prevailed in comparison with Group 2, and was 4.5 fold more compared to the control group ( $p \leq 0.001)$. A similar trend was observed with the IR-HOMA index, the values of which in Groups 1 and 2 were higher than 2.7 , which reflected the presence of IR in this category of patients. C-peptide and glucagon were also elevated in both groups regardless of the presence or absence of CVE $(p \leq 0.001)$.

Hypercholesterolemia was established in Groups 1 and 2, compared with the reference values and the control group, during studying lipid metabolism. Lipid profile data demonstrated, higher values of low density lipoprotein (LDL) were found in Group 1 - Me $4.53 \mathrm{mmol} / \mathrm{l}$ (Q25; Q75 - 3.15; 5.5) compared with group $2(p=0.01)$ and the control group $(p=0.048)$. The differences were considered statistically significant. LDL in Group 1 according to the American Heart Association, NIH and NCEP (2003) was high [17].

The level of C-reactive protein reached maximum values in Group 1 (Me - $9.65 \mathrm{mg} / \mathrm{ml}, \mathrm{p}=0.01$ ), compared with Group 2 and the control group.

The median values of the studied biomarker $\mathrm{PAl}-1$, reached the maximum values in group $1, \mathrm{Me}$ comprised $30718.6 \mathrm{pg} / \mathrm{ml}$. In Group 2, the PAl-1 biomarker also had high values and Me comprised $24692.0 \mathrm{pg} / \mathrm{ml}$. These differences were established both between Groups 1 and 2, and the control group, the differences were considered statistically significant ( $p \leq 0.001$ ) (Table 2 and Figure 1).

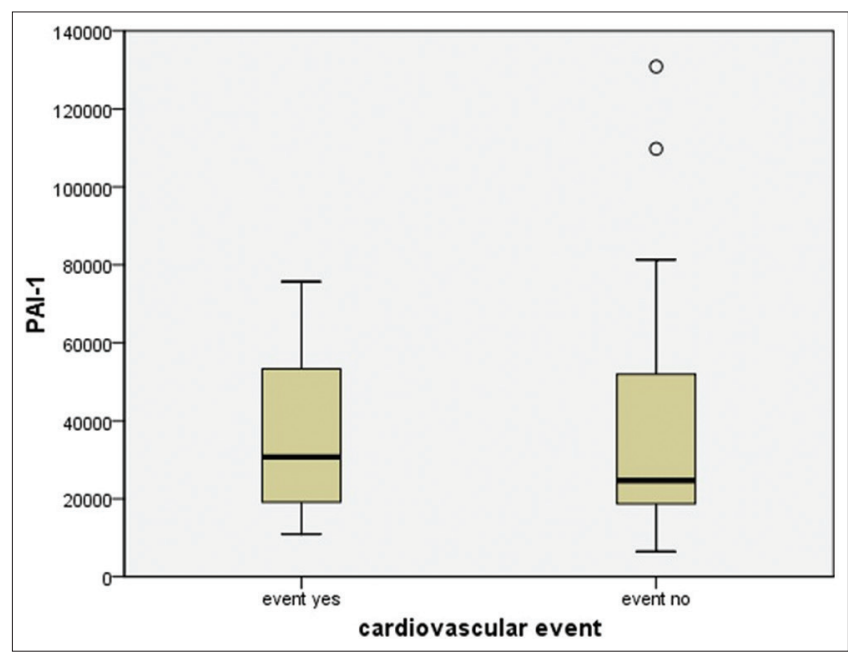

Figure 1: PAl-1 level depending on the presencelabsence of the event in patients with prediabetes

The correlation analysis of the factors affecting the increase in the level of the PAI-1 biomarker in two groups is presented in Table 3.

In both groups, relationships were found between the PAl-1 level and the concentrations of fasting glucose, glycated hemoglobin, C-peptide, IR-HOMA index, and glucagon. 
Table 2: Biochemical parameters in patients of different groups

\begin{tabular}{|c|c|c|c|c|c|}
\hline Variables & Group 1 CVE (+) & Group 2 CVE (-) & p-level & Control group & p-level \\
\hline Fasting glucose, $\mathrm{mmol} / \mathrm{l}$ & $5.8(4.97 ; 6.85)^{\star}$ & $5.7(5.4 ; 6.0)$ & 0.08 & $5.15(4.9 ; 5.77)$ & 0.03 \\
\hline HbA1c, \% & $5.8(5.7 ; 6.0)$ & $5.8(5.7 ; 6.0)$ & 0.08 & $4.8(4.6 ; 5.2)$ & 0.05 \\
\hline Insulin, mU/L & $29.26(23.56 ; 35.78)$ & $15.26(14.01 ; 18.36)$ & $\leq 0.001$ & $6.45(3.74 ; 21.77)$ & $\leq 0.001$ \\
\hline HOMA-IR & $7.72(5.24 ; 10.22)$ & $4.23(3.68 ; 6.18)$ & $\leq 0.001$ & $1.24(0.69 ; 4.68)$ & $\leq 0.001$ \\
\hline Glucagon, pg/ml & $3082.75(1146.7 ; 6111.9)$ & $1353.7(1162.4 ; 5998.1)$ & $\leq 0.001$ & 251.39 (172.3; 1479.2) & $\leq 0.001$ \\
\hline C-peptide, pg/ml & $2162.9(983.7 ; 2788.5)$ & $1919.9(934.8 ; 2034.2)$ & 0.05 & $1032.0(714.5 ; 2094.7)$ & $\leq 0.001$ \\
\hline Total cholesterol, $\mathrm{mmol} / \mathrm{l}$ & $5.73(4.80 ; 8.25)$ & $5.51(4.54 ; 6.78)$ & 0.06 & $4.94(3.62 ; 6.1)$ & $\leq 0.001$ \\
\hline LDL, mmol/l & $4.53(3.15 ; 5.5)$ & $3.73(2.67 ; 4.25)$ & 0.01 & $2.59(2.56 ; 4.44)$ & 0.048 \\
\hline $\mathrm{HDL}, \mathrm{mmol} / \mathrm{l}$ & $0.97(0.72 ; 1.14)$ & $0.99(0.84 ; 1.29)$ & 0.07 & $1.28(1.14 ; 1.43)$ & 0.05 \\
\hline Triglycerides, mmol// & $1.2(0.82 ; 1.68)$ & $1.19(0.79 ; 1.87)$ & 0.083 & $0.63(0.29 ; 1.07)$ & 0.05 \\
\hline PAI-1, пг/мл & $30718.6(17948.7 ; 53621.5)$ & 24692.0 (18525.8; 52168.2) & $\leq 0.001$ & $19461.1(8762.5 ; 27851.9)$ & $\leq 0.001$ \\
\hline C-reactive protein, mg/l & $9.65(8.34 ; 11.67)$ & $3.63(2.57 ; 4.48)$ & 0.01 & $2.5(2.26 ; 4.97)$ & 0.05 \\
\hline
\end{tabular}

CVE: Cardiovascular event, HOMA-IR: Homeostasis model for insulin resistance; LDL: Low density lipoprotein; HDL: High density lipoprotein, PAl-1: Plasminogen activator inhibitor 1. *Data presented as Me (Q25; Q75).

HbA1c: Glycated hemoglobin

The binary regression analysis has demonstrated (Figure 2), that an elevation of the PAl-1 biomarker significantly increases the risk of CVE by 3.3 fold in patients with prediabetes $(95 \% \mathrm{Cl}$ : 1.368-7.958]; ( $p \leq 0.01$ ). The risk was adjusted for gender, age, and the presence of $\mathrm{AH}$. Other factors affecting CVEs development were established. These include expected LDL-associated hyperlipidemia, and furthermore hyperglycemia and IR.

Figure 2 binary logistic regression analysis, factors affecting CVEs development in patients with prediabetes. Adjusted risk for patients with prediabetes. The dependent variable is CVE (yes/no); the adjustment was done for gender, age and presence of hypertension. Results are expressed as Odds ratio; Bars represent 95\% confidence intervals for each OR.

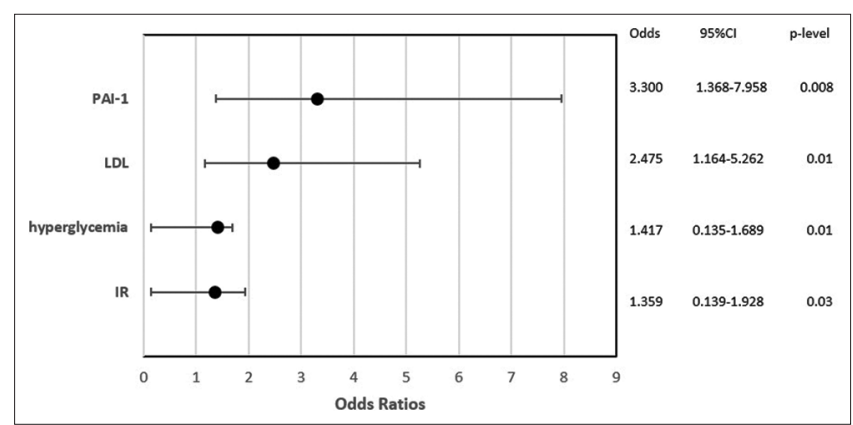

Figure 2. Binary logistic regression analysis, factors affecting cardiovascular events development in patients with prediabetes. Adjusted risk for patients with prediabetes. The dependent variable is cardiovascular event (yes/no); the adjustment was done for gender, age and presence of hypertension. Results are expressed as Odds ratio; Bars represent 95\% confidence intervals for each OR. ${ }^{*} P A I-$ 1: Plasminogen activator inhibitor, LDL: Low-density lipoprotein, IR Insulin resistance

Obtained data have been allowed us to make a linear regression model using level PAI-1 depend on presence/absence CVE in patients with prediabetes. Furthermore, we have determined factors affecting the elevation of the PAI-1 level in patients with CVE and prediabetes. in Table 4

Linear regression model results are presented

Factors influencing the increase in the level of the PAI-1 biomarker have been established (Table 4). All factors included in the regression model significantly affect the increase in the PAI-1 biomarker and were characterized by ranking from the most influencing factor to the least (fasting glycemia, presence/absence of IR, concentration of HDL, and weight circumference).

Table 3: Correlation analysis. Interrelation of PAI-1 biomarker with different parameters in groups. Spearman's correlation coefficient $(r)$

\begin{tabular}{|c|c|c|c|c|}
\hline Variables & $\begin{array}{l}\text { PAl-1, pg/ml } \\
\text { (group 1) }\end{array}$ & p-level & $\begin{array}{l}\text { PAl-1, pg/ml } \\
\text { (group 2) }\end{array}$ & p-level \\
\hline BMI, $\mathrm{kg} / \mathrm{m}^{2}$ & $0.29^{\star}$ & 0.02 & 0.11 & 0.68 \\
\hline WC, $\mathrm{cm}$ & 0.22 & 0.08 & 0.2 & 0.06 \\
\hline Systolic BP, mm of mercury & 0.08 & 0.06 & 0.08 & 0.54 \\
\hline Diastolic BP, $\mathrm{mm}$ of mercury & -0.02 & 0.06 & 0.21 & 0.06 \\
\hline Fasting glucose, $\mathrm{mmol} / \mathrm{l}$ & $0.62^{\star \star}$ & $\leq 0.001$ & $0.53^{\star *}$ & $\leq 0.001$ \\
\hline HbA1c, \% & $0.61^{* *}$ & $\leq 0.001$ & $0.62^{\star *}$ & $\leq 0.001$ \\
\hline Insulin, mU/L & 0.02 & 0.07 & $0.42^{*}$ & 0.05 \\
\hline HOMA-IR & $0.54^{* *}$ & $\leq 0.001$ & $0.59^{* *}$ & $\leq 0.001$ \\
\hline Glucagon, pg/ml & $0.58^{*}$ & 0.02 & $0.46^{\star *}$ & $\leq 0.001$ \\
\hline C-peptide, pg/ml & $0.63^{*}$ & 0.03 & $0.61^{* *}$ & $\leq 0.001$ \\
\hline Total cholesterol, mmol/l & 0.1 & 0.6 & 0.05 & 0.07 \\
\hline LDL, mmol/l & 0.28 & 0.06 & 0.01 & 0.91 \\
\hline $\mathrm{HDL}, \mathrm{mmol} / \mathrm{l}$ & -0.06 & 0.08 & -0.1 & 0.96 \\
\hline Triglycerides, mmol/l & 0.1 & 0.83 & 0.07 & 0.84 \\
\hline C-reactive protein, $\mathrm{mg} / \mathrm{l}$ & 0.07 & 0.89 & -0.08 & 0.72 \\
\hline
\end{tabular}

The linear regression model is presented as following. Substituting the values of the obtained constant, as well as the calculated coefficients for significant factors, it is possible to predict an increase in the biomarker, thus determining the practical significance of this study.

Table 4: Results of the linear regression model. Factors affecting the increase in the PAI-1 biomarker level in patients with prediabetes and absence/present of event

\begin{tabular}{lll}
\hline Variables & PAl-1; B(se) & p-level \\
\hline Fasting glycemia, mmol/I & $-0.114(0.056)$ & 0.01 \\
IR,(yes,no) & $0.287(0.118)$ & 0.01 \\
HDL, mmol/I & $-0.307(0.14)$ & 0.03 \\
WC, cm & $-0.009(0.004)$ & 0.03 \\
Constant(B) & $2.797(0.539)$ & 0.000 \\
\hline IR: Insulin resistance, HDL: High density lipoproteins, WC: Waist circumference. Note: IR was calculated
\end{tabular}

A model was made for assessing the risk of CVE (increased PAl-1 biomarker) in patients with prediabetes:

$$
\begin{aligned}
= & 2.797+(-0.114 \times \text { F.G. })+0.287 \times \mathrm{IR}+(-0.307 \\
& \times \mathrm{HDL})+(-0.009 \times \mathrm{WC})
\end{aligned}
$$

Calculation example: Assessment of the risk of CVE in patients with prediabetes (increased PAI-1 marker).

$$
\begin{aligned}
= & 2.797+(-0.114 \times 5.9)+0.287 \times 1+(-0.307 \\
& \times 1.82)+(-0.009 \times 100)=0.95=95 \%
\end{aligned}
$$


${ }^{*}$ F.G.-fasting glycemia, IR-insulin resistance, HDL-high density lipoproteins, WC-waist circumference.

Thus, in a patient with similar capillary blood glucose levels of $5.9 \mathrm{mmol} / \mathrm{l}$, with the presence of IR, with a HDL level of $1.82 \mathrm{mmol} / \mathrm{l}$ and a $W C$ of $100 \mathrm{~cm}$, the result will be 0.95 points, the PAI-1 level will be elevated with a $95 \%$ probability, in other words, with a $95 \%$ probability, a patient with the above parameters is likely to develop a non-fatal CVE in the next 10 years.

\section{Discussion}

Our study results showed that prediabetic patients have a high CVR due to IR and ED in these patients, which is confirmed by a high level of the ED marker PAl-1. The degree of IR and ED was more significantly expressed in group 1 patients with non-fatal CVE.

According to a systematic review and metaanalysis [18], Jung et al. found that high level of PAI-1 are associated with fatal CVE (myocardial infarction, stroke), and is a predictor of fatal CVE. This information is based on data of 11,557 patients from 38 corresponding studies. However, the significance of the PAl-1 biomarker as a predictor of fatal CVE has been questioned. Since other known metabolic risk factors for CVE development (metabolic syndrome, $\mathrm{IR}$, hyperinsulinism, and obesity) were not included for adjustment to the CVE risk analysis. Thus, the studies for this issue resolution are still relevant.

In addition, to the fact that the PAI-1 biomarker is a vessel factor [11], it is one of the risk factors triggering the atherosclerosis [12]. There is evidence that PAI-1 is produced by various adipose tissue cells, including preadipocytes, mature adipocytes, macrophages, endothelial, and smooth muscle cells [19], [20]. There are publicized evidences that hyperglycemia can affect the PAI-1 level. Maiello et al. [21] found that high glucose content reduces the fibrinolytic capacity of endothelial cells. Moreover, an experimental study in rats [22] by Chen et al. showed that hyperglycemia promotes the activation of the PAI-1 gene promoter in vascular smooth muscle cells. Our study has found the association of PAl-1 level and blood glucose. Moreover, these associations were found in groups both with and without CVE. This also emphasizes the effect of carbohydrate metabolism disorders (in particular, hyperglycemia in the range of $5.7-6.4 \%$ ) on the ED development in these patients.

Our study has found the relationship between the PAI-1 level and the level of glycated hemoglobin in prediabetic patients. There were no similar studies before. However, a study conducted by Wersh et al. [23] found correlations between the PAl-1 concentration and the glycated hemoglobin levels, only in patients with T2DM.

Glycemic control through diet, antihyperglycemic therapy, and insulin therapy resulted in PAI-1 lowering in prediabetic patients [24]. During a study in an animal model of diabetes [20], the diabetes was associated with elevated PAI-1 levels determined locally in the liver, epididymal fat pad, and more importantly, in the aortic wall.

The study conducted by Sobel [25] suggested that the PAI- 1 increase in the vessel walls may contribute to plaque build-up, with cellular lipid overload, and thin fibrous capsules.

There are fewstudies on the relationship between PAI-1 and prediabetes. There is evidence of increased PAl-1 levels in patients with obesity and metabolic syndrome. Thus, a study conducted by Somodi et al. found the associations of the PAl-1 biomarker and lipid metabolism indicators (LDL), but identified relationships continued to be pathogenetically unclear [7]. In contrast, our study did not receive the correlation between the PAI-1 biomarker and lipid metabolism indicators, which is probably because the subjects of the study did not have a large degree of obesity (Me; the BMI in our study was no more than $28.7 \mathrm{~kg} / \mathrm{m}^{2}$, vs. Mean \pm SD $41.9 \pm$ $\left.8.63 \mathrm{~kg} / \mathrm{m}^{2}\right)$, including less pronounced abdominal obesity (Me; WC in our study was $97.0 \mathrm{~cm}$, vs. Mean \pm SD $-119.76 \pm 16.87 \mathrm{~cm}$ ). It is a well-known fact that PAI-1 is more expressed by visceral adipose tissue compared to subcutaneous tissue [7].

A study conducted by Lalić et al. [8] found that both IR and impairment in insulin secretion response strongly correlate with coronary ED in subjects without diabetes. The level of PAl-1 was higher in patients in the ED group, as well as in a similar study [26]. In our study, the PAI-1 level was higher in the prediabetic and CVE group, the ED and IR degree was most pronounced in this group, which probably caused the CVE development. The PAl-1 level in Group 2 in prediabetic patients without CVE was comparable high as Group 1. That is why determination of this marker at the prediabetes stage or earlier to prevent both T2DM and CVE development, as well as determination of the targeting factors that affect the marker increase, is of importance.

A linear regression model was derived, which made it possible to assess the risk of CVE in patients with prediabetes, which is also a great importance for this category of patients. Thus, the development of scales for a more accurate determination of CVR in patients with prediabetes remains an urgent research issue. Scales for assessing the risk of CVE are well studied in patients without carbohydrate metabolism disorder, such as the Framingham scale [27], SCORE [28], ASCVD [29], and at the same time, for patients with prediabetes, such a technique 
does not exist. The DECODE study formulated a risk stratification for cardiovascular mortality, including fasting glucose and fasting plasma glucose tolerance status, and showed an $11 \%$ underestimation of CVR [30]. The quality of predicting CVR in patients with prediabetes is still insufficient. Based on the results of our study, an attempt was made to develop a scale that predicts the likelihood of developing ED in patients with prediabetes.

Our study was aimed at identification of groups of prediabetic patients by studying the IR, which was determined through insulin measurement, HOMA index, and C-peptide level. The HbA1c level measurement and OGTT were carried out to determine the prediabetic patient groups and exclude diabetes in patients. Therefore, we consider the lack of special methods of insulin sensitivity determination (beta cell secretory response, disposition index, acute insulin response) to be a limitation of our study. However, according to the IDF/EASD criteria [15], glycated hemoglobin measurement, fasting glycemia, and OGTT are sufficient for prediabetes and IR diagnosing. In addition, the study was aimed at paying attention to patients with prediabetes, which in most cases is undiagnosed, leading to the development of both T2DM and fatal vascular catastrophes. This study has found that PAI-1 significantly increases the CVE risk by 3.3 fold in prediabetic patients $(p \leq 0.01)$.

\section{Conclusion}

Our study attempted to evaluate the ED by determining the PAI-1 level and its association with the development of non-fatal CVE in prediabetic patients.

We received the data that confirm the presence of ED in patients with prediabetes and without CVE. Correlations of PAI-1 and abdominal obesity, IR, increased fasting glycemia, and glycated hemoglobin were found. Elevation of PAl-1 concentration is associated with a probability of CVE in patients with prediabetes.

To sum up, elevation of PAI- 1 concentration is associated with insulin resistance which leads to ED, and further development risk of CVE in patients with prediabetes. Our study also has been allowed us to develop a linear regression model to assess CVR in patients with prediabetes.

The high level of the PAl-1 biomarker in prediabetic patients determines the importance of a clinical strategy for timely detection of this category of individuals and goal-directed treatment that will prevent the ED progression and reduce the CVR. It is necessary to conduct further prospective studies and evaluate the effectiveness of therapy at the biomarker level and the development of CVE.

\section{References}

1. Cardiovascular Deseases. World Health Organization. Key Facts; 2017. Available from: https://www.who.int/news-room/ fact-sheets/detail/cardiovascular-diseases-(cvds). [Last accessed on 2021 Feb 01].

2. World Health Organization. Health of the Population of the Republic of Kazakhstan and the Activities of Health Organizations in 2017/Stat. Astana, Kazakhstan: World Health Organization; 2018. p. 354.

3. Adeva-Andany MM, Martínez-Rodríguez J, González-Lucán M. Insulin resistance is a cardiovascular risk factor in humans. Diabetes Metab Syndr. 2019;13(2):1449-55. https://doi. org/10.1016/j.dsx.2019.02.023

PMid:31336505

4. Kannel WB, McGee DL. Diabetes and cardiovascular risk factors: The Framingham study. Circulation. 1979;59(1):8-13. https://doi.org/10.1161/01.cir.59.1.8

PMid:758126

5. Selvin E, Steffes MW, Brancati FL. Glycated hemoglobin, diabetes, and cardiovascular risk in nondiabetic adults. N Engl J Med. 2010;362(9):800-11. https://doi.org/10.1056/ nejmoa0908359

PMid:20200384

6. Janus A, Szahidewicz-Krupska E, Mazur G, Doroszko A Insulin resistance and endothelial dysfunction constitute a common therapeutic target in cardiometabolic disorders. Mediators Inflamm. 2016;2016:3634948. https://doi. org/10.1155/2016/3634948

PMid:27413253

7. Somodi S, Seres I, Lőrincz H, Harangi M, Fülöp P, Paragh G. Plasminogen activator inhibitor-1 level correlates with lipoprotein subfractions in obese nondiabetic subjects. Int $\mathrm{J}$ Endocrinol. 2018;2018:9596054. https://doi.org/10.1155/2018/9596054 PMid:30002679

8. Lalić K, Nedeljković M, Jotić A, Babić R, Rajković N, Popović L, et al. Endothelial dysfunction of coronary arteries in subjects without diabetes: An association with both insulin resistance and impaired insulin secretion response. Diabetes Res Clin Pract. 2018;139:179-87. https://doi.org/10.1016/j.diabres.2018.03.005 PMid:29526680

9. Natali A, Toschi E, Baldeweg S, Ciociaro D, Favilla S, Sacca L, et al. Clustering of insulin resistance with vascular dysfunction and low-grade inflammation in Type 2 diabetes. Diabetes. 2006;55(4):1133-40. https://doi.org/10.2337/diabetes.55.04.06. db05-1076

PMid:16567539

10. Ford MA, McConnell JP, Lavi S, Rihal CS, Prasad A, Sandhu GS, et al. Coronary artery endothelial dysfunction is positively correlated with low density lipoprotein and inversely correlated with high density lipoprotein subclass particles measured by nuclear magnetic resonance spectroscopy. Atherosclerosis. 2009;207(1):111-5. https://doi.org/10.1016/j. atherosclerosis.2009.04.039

PMid:19515370

11. Adly AA, Elbarbary NS, Ismail EA, Hassan SR. Plasminogen activator inhibitor-1 (PAI-1) in children and adolescents with Type 1 diabetes mellitus: relation to diabetic micro-vascular complications and carotid intima media thickness. J Diabetes Complications. 2014;28(3):340-7. https://doi.org/10.1016/j. jdiacomp.2014.01.011 PMid:24581943

12. Tretjakovs $\mathrm{P}$, Jurka A, Bormane I, Mikelsone I, Elksne $\mathrm{K}$, Krievina $G$, et al. Circulating adhesion molecules, matrix 
metalloproteinase-9, plasminogen activator inhibitor-1, and myeloperoxidase in coronary artery disease patients with stable and unstable angina. Clin Chim Acta. 2012;413(1-2):25-9. https://doi.org/10.1016/j.cca.2011.10.009

\section{PMid:22024218}

13. Festa A, D'Agostino R Jr., Tracy RP, Haffner SM. Elevated levels of acute-phase proteins and plasminogen activator inhibitor-1 predict the development of Type 2 diabetes: The insulin resistance atherosclerosis study. Diabetes. 2002;51(4):1131-7. https://doi.org/10.2337/diabetes.51.4.1131

PMid:11916936

14. Festa A, Williams K, Tracy RP, Wagenknecht LE, Haffner SM Progression of plasminogen activator inhibitor-1 and fibrinogen levels in relation to incident Type 2 diabetes. Circulation. 2006;113(14):1753-9. https://doi.org/10.1161/ circulationaha.106.616177

PMid: 16585388

15. American Diabetes Association. 2. Classification and diagnosis of diabetes. Diabetes Care. 2017;40(1):S11-24. https://doi. org/10.2337/dc17-s005 PMid:27979889

16. Summary of the 2007 European society of hypertension (ESH) and European society of cardiology (ESC) guidelines for the management of arterial hypertension. Vasc Health Risk Manag. 2007;3(6):783-95. https://doi.org/10.1080/08037050701461084 PMid:18200799

17. Firdaus M, Asbury JM, Reynolds DW. A new paradigm of cardiovascular risk factor modification. Vasc Health Risk Manage. 2005;1(2):101-9. https://doi.org/10.2147/vhrm.1.2.101.64078 PMid:17315396

18. Jung RG, Motazedian P, Ramirez FD, Simard T, Santo PD, Visintini $S$, et al. Association between plasminogen activator inhibitor-1 and cardiovascular events: A systematic review and meta-analysis. Thromb J. 2018;16:12. https://doi.org/10.1186/ s12959-018-0166-4 PMid:29991926

19. Bastelica D, Morange $P$, Berthet $B$, Bordhi $H$, Lacroix $O$, Grino $M$, et al. Stromal cells are the main plasminogen activator inhibitor1-producing cells in human fat: Evidence of differences between visceral and subcutaneous deposits. Arterioscler Thromb Vasc Biol. 2002;22(1):173-8. https://doi.org/10.1161/hq0102.101552 PMid: 11788479

20. Pandolfi A, Cetrullo D, Polishuck R, Alberta MM, Calafiore A, Pellegrini $G$, et al. Plasminogen activator inhibitor Type 1 is increased in the arterial wall of Type II diabetic subjects. Arterioscler Thromb Vasc Biol. 2001;21(8):1378-82. https://doi. org/10.1161/hq0801.093667

PMid:11498469

21. Maiello M, Boeri D, Podesta F, Cagliero E, Vichi M, Odetti P, et al. Increased expression of tissue plasminogen activator and its inhibitor and reduced fibrinolytic potential of human endothelial cells cultured in elevated glucose. Diabetes. 1992;41:1009-15. https://doi.org/10.2337/diab.41.8.1009

PMid:1628760

22. Chen $Y Q$, Su M, Walia RR, Hao Q, Cowington JW, Vaughan DE. Sp1 sites mediate activation of the plasminogen activator inhibitor-1 promoter by glucose in vascular smooth muscle cells. J Biol Chem. 1998;273:8225-31. https://doi.org/10.1074/ jbc.273.14.8225

PMid:9525928

23. Wersh JW, Westerkuts LW, Venekamp WJ. Glycometabolic control and fibrinolysis in diabetic patients. Haemostasis. 1990;20:241-50. https://doi.org/10.1159/000216134 PMid:2242825

24. Davì G, Belvedere M, Vigneri $S$, Catalano I, Giammarresi C Roccaforte S, et al. Influence of metabolic control on thromboxane biosynthesis and plasma plasminogen activator inhibitor Type-I in non-insulin-dependent-diabetes. Thromb Haemost. 1996;76:34-7. https://doi.org/10.1055/s-0038-1650518 PMid:8819248

25. Sobel BE. Increased plasminogen activator inhibitor-1 and vasculopathy: A reconcilable paradox. Circulation. 1999;99:2496-8. https://doi.org/10.1161/01.cir.99.19.2496

26. Erzen B, Sabovic M. In young post-myocardial infarction male patients elevated plasminogen activator inhibitor-1 correlates with insulin resistance and endothelial dysfunction. Heart Vessels. 2013;28:570-7. https://doi.org/10.1007/ s00380-012-0287-9

PMid:23001714

27. D'Agostino RB Sr., Vasan RS, Pencina MJ, Wolf PA, Cobain M, Massaro JM, et al. General cardiovascular risk profile for use in primary care. The Framingham heart study. Circulation. 2008;117(6):743-53. https://doi.org/10.1161/ circulationaha.107.699579

PMid: 18212285

28. European Guidelines on CVD Prevention in Clinical Practice 2016 Eur J Prev Cardiol. 2016;23(11):1-96. https://doi. org/10.1177/2047487316653709 PMid: 27353126

29. Arnett $D K$, Blumenthal RS, Albert $M A$, Buroker $A B$, Goldberger ZD, Hahn EJ, et al. 2019 ACC/AHA guideline on the prevention of cardiovascular disease: A report of the American college of cardiology and American heart association task force on clinical practice guidelines. Circulation. 2019;140(11):e56395. https://doi.org/10.1161/cir.0000000000000725 PMid:30879355

30. Zhang L, Qiao Q, Tuomilehto J, Hammar N, Alberti KG, Eliasson M, et al, DECODE Study Group. Blood lipid levels in relation to glucose status in European men and women without a prior history of diabetes: The DECODE Study. Diabetes Res Clin Pract. 2008;82(3):364-77. https://doi.org/10.1016/j. diabres.2008.08.022

PMid:18922596 